\title{
STUDIES ON THE IMPROVEMENT OF MECHANICAL AND THERMAL PROPERTIES OF NYLON 66 BY USING MULTI-WALLED CARBON NANOTUBES NANO COMPOSITES
}

\section{BHUKYARAJAM}

Research Scholar, University College of Technology, Osmania University, Hyderabad, India

Received: May 19, 2020; Accepted: Jun 09, 2020; Published: Jul 25, 2020; Paper Id.: IJMPERDJUN2020455

\section{INTRODUCTION}

This project work is the study of mechanical and thermal properties of nylon 66/MWNTS nano composites ${ }^{[1]}$. Mainly nanotechnology deals with small structures or small sized materials. The typical dimensions spans from subnano meter to several hundred nano meters ${ }^{[2][3]}$. A nano meter is one billionth of a meter, or $10^{-9} \mathrm{~m}$.

A commercially available nylon66 / MWNTs nano composite master batch $(85+15 \%)$ was diluted with PA66 to get $0.5,1,1.5,2 \mathrm{wt} \%$ of nano composites ${ }^{[3]}$. Melt compounding is the best method for mixing of nylon 66 and MWNTs which is carried in injection molding machine.

Nylon 66 (poly hexamethylene diamine adipamide) is a polyamide made from adipic acid and hexamethylene diamine. It has a dense structure and melting point is $265^{\circ} \mathrm{C}$. It has unique properties rather than other polymers. On the other hand, Nylon 66 is a thermoplastic, which can be repeatedly melted and molded again and again by simple heating

The unique mechanical and thermal properties of MWNTs make very attraction for fabricating of new advanced materials of nylon $66^{[5]}{ }^{[15]}$. The combination of nylon 66 and MWNTs showing improvement in mechanical and thermal properties, Compared to other polymer with MWNTs ${ }^{[16]}$. The outstanding combination is done with the help of injection molding to achieve successful commercial developments in mixing [17] [18]. 


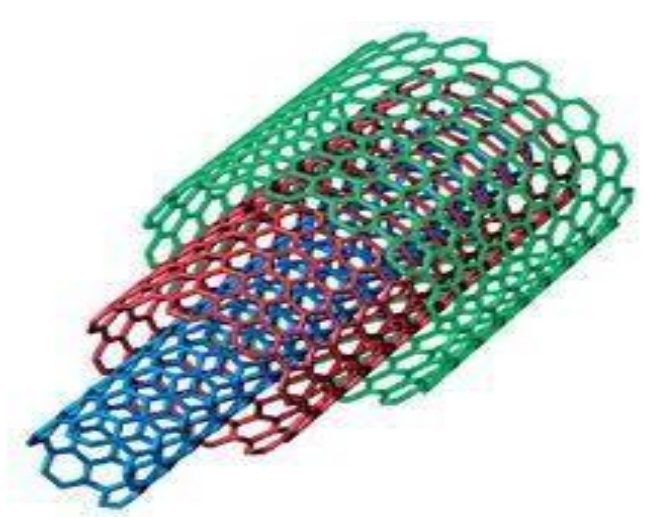

Figure 1: Multi Walled Carbon Nanotube.

\section{EXPERIMENT}

\subsection{Materials}

Nylon 66 / MW NTS nano composite master batch PLASTICYL PA1501 was purchased from Nanocyl S.A.RUE DE L'Fssor 4 (real density $1165 \mathrm{G} / \mathrm{L}$, MFI $\left.300^{\circ} \mathrm{C}, 20 \mathrm{kgn}, 4 \mathrm{~mm}-0.8\right)$. Nylon $66\left(1.14 \mathrm{~g} / \mathrm{cm}^{3}\right.$ at $25^{0} \mathrm{C}$, melting point $=263.35$ ) purchased from sigma Aldrich was used to prepare nano composite.

\subsection{Sample Preparation}

\section{Procedure}

Nylon 66 has a highly hygroscopic nature ${ }^{[23]}$. So it has to be predried at $80^{\circ} \mathrm{C}$ for $3 \mathrm{hrs}$ in a hot air oven ${ }^{[1][19][20]}$. Nylon $66 /$ MWNTs nano composite is prepared by dilution of nylon 66 / MWNTs Master batch with nylon 66. For 0.5\% of nylon 66 / MWNTs nano composite, add 2900 gms of nylon 66 and 100 gms of master batch. These two are fed in a injection molding machine with high speed.

Table 1

\begin{tabular}{|c|c|c|c|c|c|c|c|c|}
\hline $0.5 \%$ & dilution & - & $2900 \mathrm{gms}$ & nylon & $66+100 \mathrm{gms}$ & nylon & $66 /$ MWNTs & nano composite \\
\hline $1 \%$ & dilution & - & $2800 \mathrm{gms}$ & nylon & $66+200 \mathrm{gms}$ & nylon & $66 /$ MWNTs & nano composite \\
\hline $1.5 \%$ & dilution & - & $2700 \mathrm{gms}$ & nylon & $66+300 \mathrm{gms}$ & nylon & $66 /$ MWNTs & nano composite \\
\hline $2 \%$ & dilution & - & $2600 \mathrm{gms}$ & nylon & $66+400 \mathrm{gms}$ & nylon & $66 /$ MWNTs & nano composite \\
\hline
\end{tabular}

\subsection{Injection Molding}

Injection molding is a manufacturing process for producing different parts from both thermoplastic and thermosetting plastic or other materials including elastomers, metals, glasses ${ }^{[15][16]}$. Here 2900 gms of nylon66 and 100 gms nylon66/MWNTs master batch were fed through a hopper into a heated barrel with a reprocating screw [19][20].THE samples are made for both pure nylon 66 and nylon 66 / MWNTs nano composites. The injection speed is at $70 \mathrm{~cm}^{3} / \mathrm{s}$ and the material melts at $270{ }^{\circ} \mathrm{C}^{[20][21]}$. The screw delivers the raw material forward, mixes and homogenizes the thermal and viscous distributions of the polymer he heating barrel is $200-240-270-300^{\circ} \mathrm{C}$. When enough material has gathered, the material is forced at high pressure about 70 bar The mould is at $80^{\circ} \mathrm{C}$.For each test 10 samples are made by using different moulds. Holding pressure is $35 \mathrm{bar}$. The products were dried in an oven for $40 \mathrm{hrs}$ at $25^{\circ} \mathrm{C}$ prior to testing of properties ${ }^{[24]}{ }^{[25]}$. For nylon 66 the temperature barrel changes. .i.e. 180-220-235-265

Table 2 shows wt \% of MWNTs in nylon 66The flexural strength results are in Table 2. There is straight increase with increase in MWNTs percentages. The bending strength of nylon 66 MWNTs nano composites were very higher than compared to pure nylon 66 as shown in Figure 2. The reason is there is a very good attraction between the atoms of nylon 
66 and MWNTs. So the bonds are nearer and regularly arranged [61]. Hence flexural strength is increased.

Table 2: Tensile Strength of Nylon 66 and Nylon 66 / Mwnts Nano Composite Flexural Strength of Nylon 66 and Nylon 66 / Mwnts

\begin{tabular}{|c|c|c|c|c|}
\hline $\begin{array}{c}\text { Pure nylon } \\
\mathbf{2}\end{array}$ & $\begin{array}{c}\text { Dilution to 0.5 } \\
\mathbf{6 6}(\mathbf{N} / \mathbf{M m})\end{array}$ & $\begin{array}{c}\text { Dilution to 1.0 } \\
\mathbf{2}(\mathbf{N} / \mathbf{M m})\end{array}$ & $\begin{array}{c}\text { Dilution to 1.5 } \\
\mathbf{2}(\mathbf{N} / \mathbf{M m})\end{array}$ & $\begin{array}{c}\text { Dilution to 2.0 \% } \\
\mathbf{2}(\mathbf{N} / \mathbf{M m})\end{array}$ \\
\hline 81.75 & 105.312 & 120.848 & 135.396 & 171.38 \\
\hline
\end{tabular}

Table 3

\begin{tabular}{|c|c|c|c|c|}
\hline $\begin{array}{c}\text { Pure Nylon } \\
\text { (Mpa) }\end{array}$ & $\begin{array}{c}\text { Dilution to 0.5\% } \\
\text { (Mpa) }\end{array}$ & $\begin{array}{c}\text { Dilution to 1.0 \% } \\
\text { (Mpa) }\end{array}$ & $\begin{array}{c}\text { Dilution To 1.5 \% } \\
\text { (Mpa) }\end{array}$ & $\begin{array}{c}\text { Dilution to 2.0 \% } \\
\text { (Mpa) }\end{array}$ \\
\hline 117.712 & 231.592 & 251.826 & 270.59 & 293.092 \\
\hline
\end{tabular}

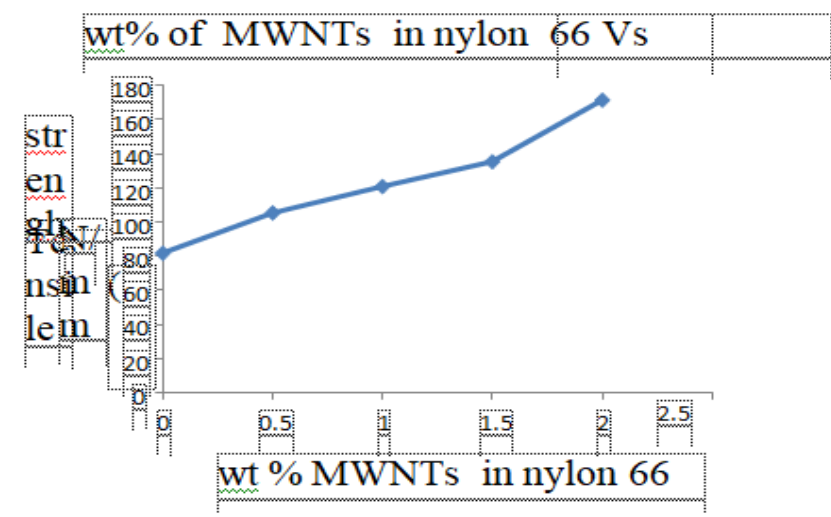

Figure 2

\subsection{Tensile Strength}

Wt \% of MWNTs in nylon 66 Vs Izod impact strength Impact strength values of nylon 66 and nylon 66 / MWNTs nano composite were shown Table 4. The impact strength of nano composites was increased as shown in Figure 3.The impact strength of the material depends on the molecular orientations and flexibility of the material ${ }^{[62]}$. Due to addition of MWNTs orientation of molecules increases. So at sudden shocks also it requires more energy to break the sample. Impact strength of nylon 66 / MWNTs nano composite increases with increase in of MWNTs loadings.

Table 6 shows the addition of MWNTs contents with nylon 66 increases the hardness value because it may decrease the mobility of the polymer molecule and segment chain ${ }^{[63]}$. The molecules are regularly arranged in nylon 66/ MWNTs nano composite. The fig 4.4 shows the increasing values of hardness with increasing percentage of MWNTs.

Table 4

\begin{tabular}{|c|c|c|c|c|}
\hline Pure Nylon 66 & Dilution to 0.5 \% & Dilution to 1.0 \% & Dilution To 1.5 \% & Dilution to 2.0 \% \\
\hline 64.54 & 91.4966 & 135.166 & 148.9566 & 155.04 \\
\hline
\end{tabular}




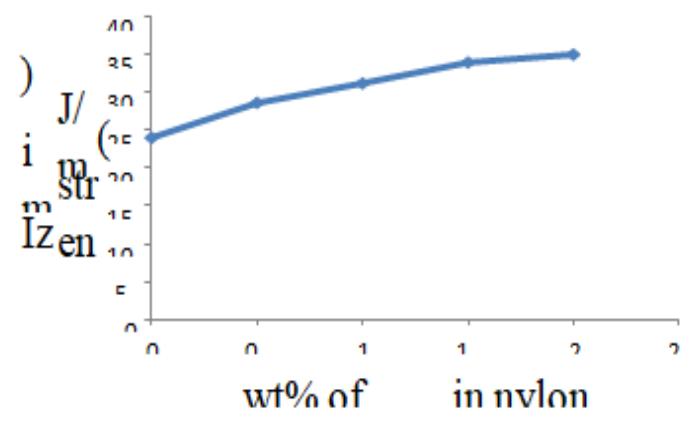

Figure 3

Table 5: Hardness of Nylon 66 and Nylon

\begin{tabular}{|l|c|c|c|}
\hline \multirow{2}{*}{ Material } & \multicolumn{2}{|c|}{ Revolutions Per 15 Sec } & \multirow{2}{*}{ Hardness } \\
\cline { 2 - 3 } & Major Load & Minor Load & \\
\hline Nylon 66 & 2 & 1 & $75 \mathrm{M}$ \\
\hline $0.5 \%$ nano composite & & 1 & $90 \mathrm{M}$ \\
\hline $1 \%$ nano composite & 3 & 3 & $100+10=110 \mathrm{M}$ \\
\hline $1.5 \%$ nano composite & 3 & 3 & $100+25=125 \mathrm{M}$ \\
\hline $2 \%$ nano composite & 3 & 3 & $100+40=140 \mathrm{M}$ \\
\hline
\end{tabular}

Table 6: 66 / MWNTs Nano Composite Comparision

\begin{tabular}{|c|c|c|c|c|}
\hline Pure nylon 66 & Dilution to 0.5 \% & Dilution to 1.0\% & Dilution to 1.5 \% & Dilution to 2.0 \% \\
\hline $75 \mathrm{M}$ & $90 \mathrm{M}$ & $110 \mathrm{M}$ & $125 \mathrm{M}$ & $140 \mathrm{M}$ \\
\hline
\end{tabular}

wt\% of MWNTs in Nylon 66 Vs Hardness

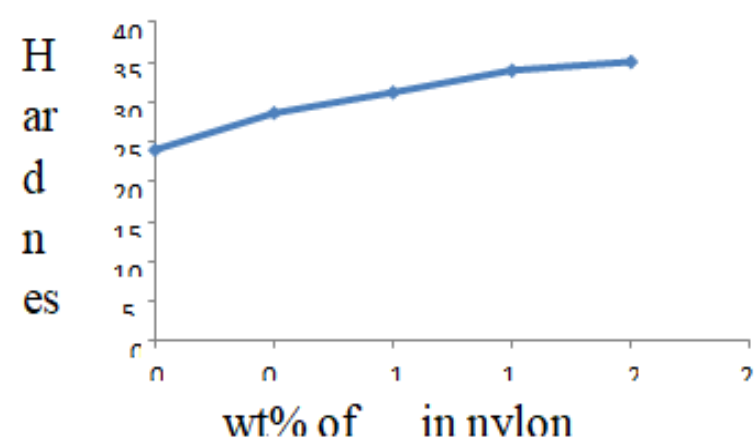

Figure 4

2.5. Heat deflection temperature

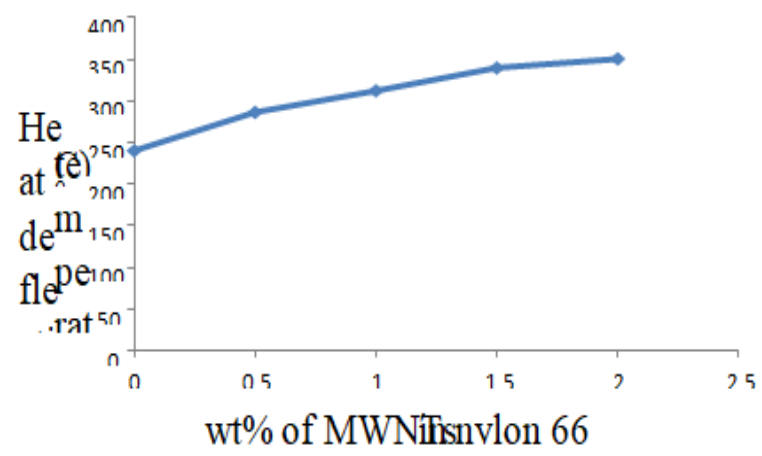

Figure 5: Heat Deflection. 


\subsection{Temperature of Nylon 66 and Nylon 66 / MWNTs Nano Composite Comparision}

With addition of MWNTs to nylon 66 increases the heat deflection temperature. due to decreasing the segmental mobility of the polymer molecule and increasing the crystallinity ${ }^{[64]}$. So as a result the composite is more thermo stable and increased continuous service temperature.

The vicat softening points of these nano composites are increased while increasing the percentages of MWNTs. The values are summarized in the Table 7.Mainly VSP depends on amount of test load and rate of heating ${ }^{[65]}$. For engineering materials $5 \mathrm{Kg}$ load is applied and therate of heat increasing is carried uniformly throughout the process. And thus it resulted an increase in this VSP. The Figure 6 shows the increased values. \% Moisture content

The strength of the nylon 66 / MWNTs nano composite is increased while increasing the MWNTs content. The crystallinity of the nano composite is increased because the molecules are regularly arranged ${ }^{[66]}$. The tensile strength and flexural strength are related to moisture content. The Figure 7 shows the decreasing line Melting point

Melting point depends on the intermolecular force of attraction between molecules and segmental mobility of molecules. With increasing the MWNTs content the molecular mobility will be restricted ${ }^{[67]}$. This may due to increase the crystallinity of the polymer. As a result the melting point of the composite increases with increasing the MWNTs content which is clearly observed in following Figure 8.

Table 7: Vicat Softening Point

\begin{tabular}{|c|c|c|c|c|}
\hline Pure nylon $66\left({ }^{\circ} \mathrm{C}\right)$ & Dilution to 0.5 \% $\left({ }^{\circ} \mathrm{C}\right)$ & Dilution to $1.0 \%\left({ }^{\circ} \mathrm{C}\right)$ & Dilution to $1.5 \%\left({ }^{\circ} \mathrm{C}\right)$ & Dilution to $2.0 \%\left({ }^{\circ} \mathrm{C}\right)$ \\
\hline 240 & 286.16 & 311.966 & 339.5 & 350.16 \\
\hline
\end{tabular}

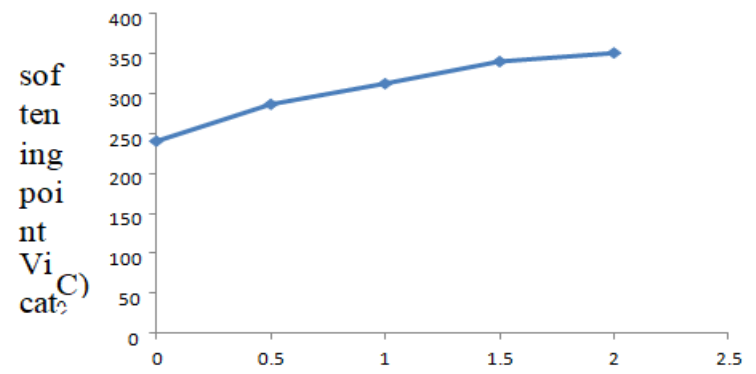

wt $\%$ of MWNTs in nylon $66 \mathrm{Vs}$ Vicat softening point wt $\%$ of MWNTs in nylon 66

Figure 6: Vicat Softening Point of Nylon 66 and Nylon 66 / Mwnts Nano Composite Comparision.

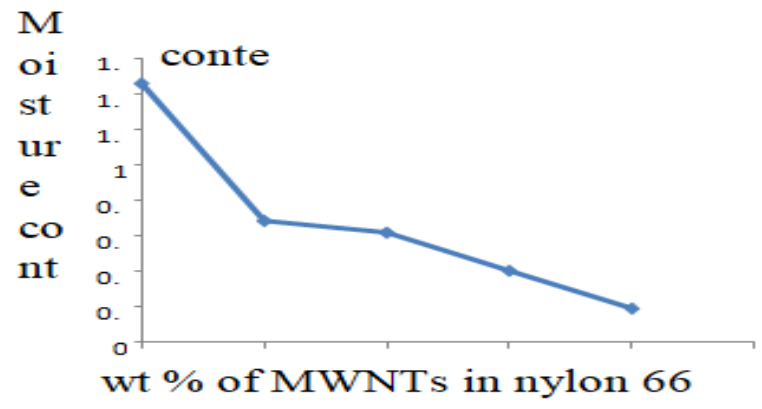

Figure 7: Moisture Content of Nylon 66 and Nylon 66 / Mwnts Nano Composite. 
Table 8

\begin{tabular}{|c|c|c|c|c|}
\hline Nylon $66\left({ }^{\mathbf{0}} \mathrm{C}\right)$ & $\begin{array}{c}\mathbf{0} \% 5 \text { Nano } \\
\text { Composite }\left({ }^{\mathbf{0}} \mathrm{C}\right)\end{array}$ & $\begin{array}{c}1 \% \text { Nano } \\
\text { Composite }\left({ }^{\mathbf{0}} \mathrm{C}\right)\end{array}$ & $\begin{array}{c}1 \% 5 \text { Nano } \\
\text { Composite }\left({ }^{\mathbf{0}} \mathrm{C}\right)\end{array}$ & $\begin{array}{c}2 \% \text { Nano } \\
\text { Composite }\left({ }^{\mathbf{0}} \mathrm{C}\right)\end{array}$ \\
\hline 265 & 279 & 283 & 294 & 300 \\
\hline
\end{tabular}

\section{wt $\%$ of MWNTs in nvlon 66 Vs Meeltint}

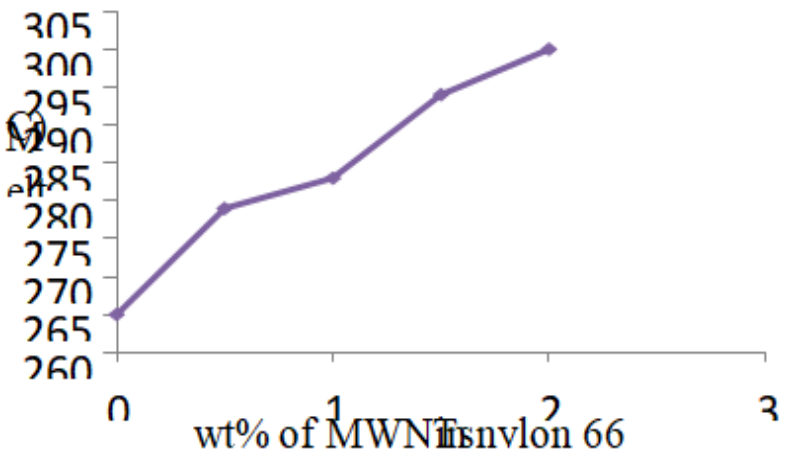

Figure 8: Melting Point of Nylon 66 and Nylon 66/Mwnts Nano Composite.

\section{CONCLUSIONS}

It was observed that the mechanical properties such as tensile strength, flexural strength, Izod impact strength and hardness of nylon 66/MWNTs nano composites increased with increase of MWNTs contents for each composition. Thermal properties such as HDT, VSP, and melting point increased with the increase of MWNTs contents for each nano composites. Moisture content decreased by increasing

\section{REFERENCES}

1. Jae-Hong Park, Gil-Hwan Son, Jin-San Moon, Jae-Hee Han, Alexander S.Berdinsky, D.G. Kuvshinov, Ji-BeomYoo, Chong-Yun Park, J. Vac. Sci.Technol., B 23 (2005) 749.

2. Y.J. Jung, G.H. Son, J.H. Park, Y.W. Kim, Alexander S. Berdinsky, J.B.Yoo, C.Y. Park, Diamond Relat. Mater. 14 (2005) 2109. 3. Shuying Yang, Karen Lozano, Azalia Lomeli, Heinrich D. Foltz, Robert Jones, Compos., A 36 (2005) 691.

3. Panneerselvam, K., and K. Lenin. "Study on hardness and micro structural characterization of the friction stir welded Nylon 6 plate." Int J MechEng, 2, 5162 (2013).

4. J.S. Moon, J.H. Park, T.Y. Lee, Y.W. Kim, J.B. Yoo, C.Y. Park, J.M. Kim, K.W.Jin,DiamondRelat. Mater. 14 (2005) 1882.

5. C. Park, Z. Ounaied, K.A.Watson, R.E. Crooks, J. Smith Jr., S.E. Lowther J.W. Connell, E.J. Siochi, J.S. Harrison, T.L. St.Clair, Chem. Phys. Lett. 364 (2002) 303.

6. SHAMIN, MK. "MORPHOLOGICAL AND STRUCTURAL STUDY OF FRICTION STIR WELDED THIN AA6061-T6 SHEETS. "International Journal of Mechanical Engineering (IJME) ISSN (P): 2319-2240; ISSN (E): 2319-2259 Vol. 6, Issue 5, Aug - Sep 2017; 19-24.

7. E.J. Ra, K.H.An, K.K. Kim, S.Y.Jeong,Y.H. Lee, Chem. Phys. Lett. 413 (2005) 188.

8. Drexler, K. Eric (1986). Engines of Creation: The Coming Era of Nanotechnology. Doubleday. ISBN 0-385-19973-2.

9. Drexler, K. Eric (1992). Nanosystems: Molecular Machinery, Manufacturing, and Computatin. NewYork: John Wiley \& Sons. ISBN 0-471-57547-X.

10. Apply nanotech to up industrial, agri output, The Daily Star (Bangladesh), 17April 2012. 
11. SRIMURUGAN, R., B. VIJAYA RAMNATH, and C. ELANCHEZHIAN. "AN INVESTIGATION ON MECHANICAL BEHAVIOUR OF NYLON 6-POLYCARBONATE HYBRID COMPOSITE."International Journal of Mechanical and Production Engineering Research and Development (IJMPERD) ISSN(P): 2249-6890; ISSN(E): 2249-8001 Vol. 8, Issue 6, Dec 2018, 525-532.

12. Cristina Buzea, Ivan Pacheco, and Kevin Robbie (2007). "Nanomaterials and Nanoparticles: Sources and Toxicity".Biointerphases 2(4): MR17- 71. doi:10.1116/1.2815690.PMID 20419892.

13. Binnig, G.; Rohrer, H. (1986). "Scanning tunneling microscopy". IBM Journal of Research and Development 30: 4.

14. "Press Release: the 1996 Nobel Prize in Physics". Nobelprize.org. 15 October 1986. Retrieved 12 May 2011.13. Kroto, H. W.; Heath, J. R.; O'Brien, S. C.; Curl, R. F.; Smalley, R. E. (1985). "C60: Buckminsterfullerene". Nature318 (6042):162163. Bibcode 1985Natur.318..162K.doi:10.103 8/318162a0.

15. Gangawane, Prashant, and Usha Sayed. "Innovative Use Of Disused Doxycycline Hydrochloride to Dye Silk." International Journal of Medicine and Pharmaceutical Sciences 2014; 4 (3): 5358.

16. Wang, X.; Li, Qunqing; Xie, Jing; Jin, Zhong; Wang, Jinyong; Li, Yan; Jiang, Kaili; Fan, Shoushan (2009). "Fabrication of Ultralong and Electrically Uniform Single-Walled Carbon Nanotubes on Clean Substrates". Nano Letters 9 (9): $3137-3141$. doi:10.1021/nl901260b. PMID 19650638.

17. Gullapalli, S.; Wong, M.S. (2011). "Nanotechnology: A Guide to NanoObjects". Chemical Engineering Progress 107 (5): $28-32$.

18. Mintmire, J.W.; Dunlap, B.I.; White, C.T. (1992). "Are Fullerene Tubules Metallic?". Phys. Rev. Lett. 68 (5): $631-634$. doi:10.1103/PhysRevLett.68.631. PMID 10045950.

19. Dekker, C. (1999). "Carbon nanotubes as molecular quantum wires". Physics Today 52 (5): 22-28. doi:10.1063/1.882658. 18. Martel, R.; Derycke, V.; Lavoie, C.; Appenzeller, J.; Chan, K.; Tersoff, J.; Avouris, Ph. (2001). "Ambipolar Electrical Transport in Semiconducting Single-Wall Carbon Nanotubes". Phys. Rev. Lett. 87 (25): 256805. doi:10.1103/PhysRevLett.87.256805. PMID 11736597.

20. Baughman RH, Zakhidov AA, de Heer WA. Science BounphanhTonpheng,University F Umeå,Sweden U Umeå, $2011 ; 297: 787$.

21. Thostenson ET, Ren ZF, Chou TW. Compos SciTechnol 2001; 61:1899. 

